\title{
The application of arbuscular mycorrhizal fungi to micropropagation systems: an opportunity to reduce chemical inputs
}

\author{
John E. Hooker, Silvio Gianinazzi, Mauritz Vestberg, Jose M. Barea and David Atkinson
}

\begin{abstract}
Hooker, J.E. ${ }^{~}$, Gianinazzi, S. ${ }^{2}$, Vestberg, M. ${ }^{3}$, Barea, J.M. ${ }^{4}$ \& Atkinson, D. ${ }^{5}$ 1994. The application of arbuscular mycorrhizal fungi to micropropagation systems: an opportunity to reduce chemical inputs. Agricultural Science in Finland 3: 227-232. (' Soil Biology Unit, Land Resources Department, Mill of Craibstone, Bucksburn, Aberdeen, AB2 9TS, UK, ${ }^{2}$ INRA-CNRS, Laboratoire de Phytoparasitologie, Station de Génétique et d'Amelioration des Plantes, INRA, BV 1540, F-21034 Dijon Cedex, France, ${ }^{3}$ Agricultural Research Centre of Finland, Laukaa Research and Elite Plant Unit, FIN-41340 Laukaa, Finland, ${ }^{4}$ CSIC, Estación Experimental del Zaidin, Departmento de Microbiologia, Prof Albareda I, E-18008 Granada, Spain, ${ }^{5}$ SAC, West Mains Road, Edinburgh EH9 3JG, UK.)
\end{abstract}

Key words: micropropagation, sustainability

\section{Introduction}

Over the past 15 years the use of in vitro micropropagation as a technique for the growth and multiplication of plants has increased rapidly and today it is used not only as a research tool but also as a technique for commercial plant production. The identification of the correct media and cultural conditions for the organised growth of plant tissues in vitro has been the subject of much research and it is now possible to identify these for many species. This success means that it is now possible to micropropagate in vitro a wide range of plant species including annual and perennial ornamentals, timber trees, ferns and several important crop plants such as banana, pineapple, avocado and potato. Consequently micropropagation is now widely applied and 175 million plants were cultured in this way during 1990 in Europe alone (O'RIORDAIN 1990). The reasons for utilising micropropagation techniques in commercial production systems are varied. One major benefit is the capacity to implement the end points of breeding programmes rapidly with large numbers of cloned micropropagated plants capable of being produced in a relatively short time. Another is that micropropagated plantlets are usually free of disease due to their initiation from meristems and maintenance in axenic conditions. Furthermore, in perennial ornamental and woody plants inbred lines are not available and good cultures can only be maintained by vegetative propagation or micropropagation (DE Klerk and Ter Brugge 1993). For most plant species this results in rapid multiplation and production of high quality, uniform plants free of disease.

However in the weaning stage plants are subject to severe environmental stress due to poor root, shoot and cuticular development. Although some plant species can withstand this acclimitization stress well, due to the rapid onset of root and shoot growth, others cannot and this results in an extended weaning stage often accompanied by high losses and large increases in fertiliser and pesticide chemical inputs. Woody plants pose a particular problem in that they are inerently difficult to root and this often limits the commer- 
cial production of some genotypes (DAVIS et al. 1988). Humidity tents, anti-transpirants, additional light and $\mathrm{CO}_{2}$ enrichment have all been employed to increase survival but with only limited success.

\section{The application of arbuscular mycorrhizal fungi}

A biological solution has now been identified as it has been demonstrated that inoculation with arbuscular mycorrhizal fungi (AMF) can result in the growth enhancement of a wide range of micropropagated plantlets (eg CHAVEZ and FERRERA-CERRATO 1990) and more importantly can significantly improve the establishment and growth of these difficult to root species eg Avocado (AzCon-Aguilar et al. 1992). These symbiotic fungi normally colonise roots of most plant species, including the vast majority of those currently micropropagated. They form specialised structures in the root, arbuscules - hence the name arbuscular mycorrhizal fungi - and sometimes vesicles, an external mycelium and spores (Figure 1). These associations between the root and the AMF are termed mycorrhizas and benefit the plant by enhancing nutrient and water uptake and providing protection to colonised plants against pathogens. In natural systems plants are normally colonised by the fungi and thus have mycorrhizas. However, in the in vitro stage of micropropagation these fungi are removed, along with all other microorganisms. Furthermore, substrates used in the post vitro stages of the micropropagation process are normally treated in order to remove potential pathogens and at the same time this also removes the beneficial AMF. Plants produced using traditional micropropagation methods will thus not normally have the benefits of the symbiosis and only by re-introduction of the fungi will the benefits be acquired. Of the three stages in the micropropagation process ie in vit$r o$, weaning and post weaning results to date show that inoculation during the weaning phase results in optimal colonisation and benefits (RAVOLANIRINA et al. 1989).

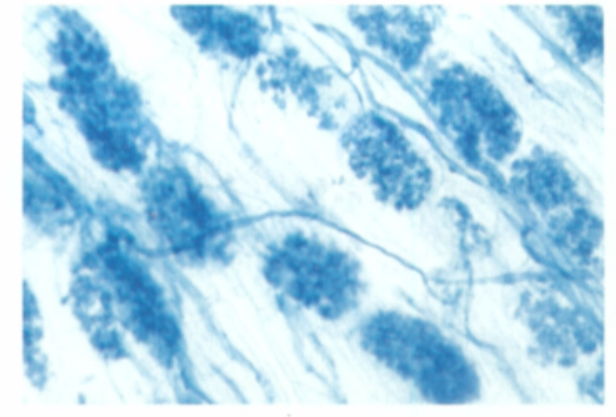

Fig. 1. Arbuscules in roots of strawberry (x 320) (Photo: Mauritz Vestberg).

Research over many years has identified three major principles which are likely to determine the extent of benefits to a plant as a result of the symbiosis. Firstly that, in general, plants benefit primarily due to an increased supply of phosphorous and benefits decrease with increasing supplies of soluble phosphate (Figure 2). Secondly, some plant species are more dependent than others, with more dependent and therefore responsive species tending to have coarser roots and fewer root hairs (GIANINAZZI-PEARSON 1986). And thirdly that isolates of the fungi differ in their ability to benefit plants and this can be modified by both plant species and environmental conditions.

Research has now demonstrated that the same principles can also be applied to micropropagated plants. Responses to inoculation are dependent both on the species of the micropropagated plant (SALAmANCA et al. 1992) and AMF species (WiLliams et al. 1992). The use of controlled release fertilisers has been investigated with a view to limiting the influence of high phosphate levels, often applied to plantlets during weaning, on the establishment of the symbiosis. These formulations have been successful with WiLliams et al. 1992 demonstrating that the growth of AMF inoculated strawberries to which only $25 \%$ of the minimum recommended rate of osmocote, a controlled release fertiliser, had been added had the same dry weight at harvest of non-inoculated plants receiving the full amount. Furthermore, 




Increasing phosphate

Fig. 2. Theoretical curves showing the response of arbuscular mycorrhizal (-) and non-arbuscular mycorrhizal plants (-- ) to increasing substrate phosphate, (after GIANINAZZI-PEARSON 1986).

BLAL et al. (1990) showed with micropropagated oil palm that in mycorrhizal plants the coefficient of fertiliser utilisation is increased. This ranged from almost 3 times for superphosphate to 4 times for rock phosphate. The chemical and physical composition of the substrate has also been shown to be important to colonisation and subsequent benefits (BRANZANTI et al. 1991) and it is important therefore that these are also optimised in any micropropagation-AMF system.

The effects of AMF on plants are however, not limited to nutrition alone. There are many reports of the effects of colonisation on a plant's susceptibility to pathogens. The vast majority report a protective effect against fungal pathogens and there are also reports of protection against nematodes (review 1994). These benefits are likely to be of even greater importance in micropropagation systems where plants are at an even greater risk due to their increased susceptibility due to poor cuticular and root development and consequent need to be maintained within a high humidity environment. The application of AMF therefore offers not just an opportunity to reduce fertiliser inputs but also reduce the use of pesticides.

\section{Mechanism of action}

Until recently the beneficial effects of colonisation by AMF on plant nutrition were considered to be solely due to the increased surface area provided by the external mycelium. This provides an increased capacity to explore the soil volume and there is also evidence that colonisation increases the absorbing capacity of the roots themselves (Gray and Gerdeman 1969, BowEN et al. 1975). However, research has now demonstrated significant effects of colonisation on the structural morphology of plant roots (eg BERTA et al. 1990, Shellenbaum et al. 1991, Hooker et al. 1992) usually resulting in root systems which are more branched and therefore likely to have a higher capacity for the uptake of nutrients and water. What causes these changes is not known, but as AMF produce hormones (BAREA and AzCONAGUILAR 1992), they may be involved. However, whatever the cause, given the form of the induced changes it is likely that the benefits will be greater in plants suffering from environmental stresses which occur in the weaning phase of micropropagation.

There is no real understanding of the factors which are important in the enhanced protection of AMF colonised plants against root pathogens. The literature suggests many possible mechanisms, including enhanced nutrition (DAvis et al. 1979), production of isoflavonoid compounds (MoRAnd et al. 1984) and changes in mycorrhizal bacterial populations (MEYER and LINDERMAN 1986). It is also likely that induced changes in root morphology and gene expression are at least partly responsible (discussed in BAREA et al. 1993 and HOOKER et al. 1994). It is probable that in most cases the protection conferred will be the result of a number of different mechanisms, their relative importance depending on several plant, fungal and environmental factors.

\section{The future}

From a commercial point of view the most exciting conclusions of micropropagation-AMF re- 


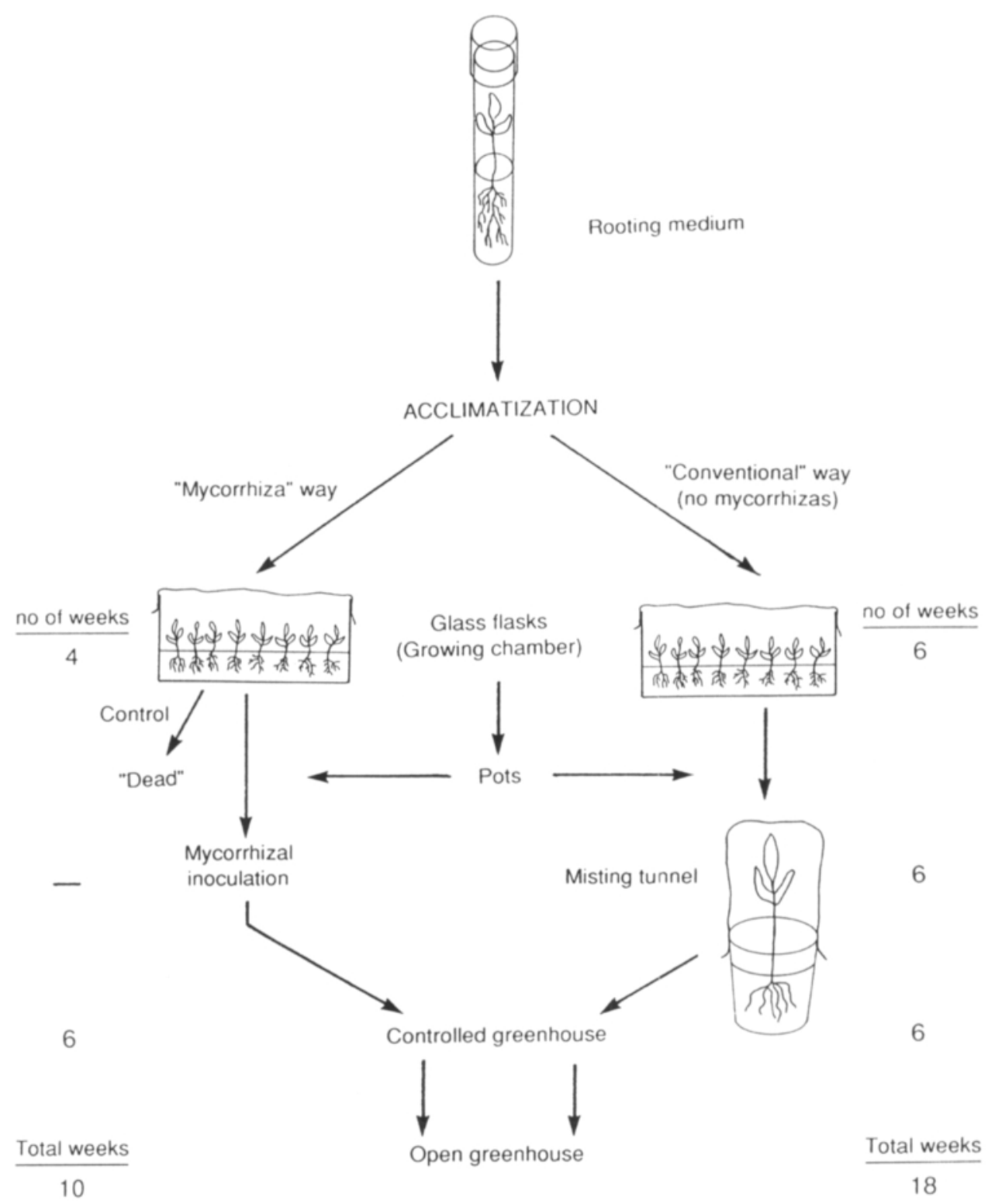

Fig. 3. Schematic of the micropropagation cycle for mycorrhizal and non-mycorrhizal plants (redrawn from SALAMANCA et al. 1992).

search is firstly evidence for protection against pathogens and secondly the impact of inoculation on the length of the production cycle. SALAmanca et al. 1992 has demonstrated the latter. They showed that inoculation of the legumes Anthyllis cytisoides and Spartium junceum with the AMF Glomus fasciculatum reduced the length of the production cycle from 18 to 10 weeks (Figure 3).
Uosukainen and Vestberg (this volume) have identifed a similar trend with the production cycle for crabapple reduced by $20-25 \%$ when inoculated. The savings of energy and chemical inputs due to a significantly shorter production cycle are a major incentive to introduce AMF. Furthermore, uniformity has also been shown to increase as a result of inoculation (BRANZANTI et 
al. 1992) and blocking of shoot apical growth at transplanting prevented (BERTA et al. 1994). These provide further major benefits to the commercial grower.

Clearly if AMF fungi are to be introduced into and function within commercial micropropagation systems and thus reduce chemical inputs there are two requirements which must first be met. Firstly, there needs to be a readily available supply of inoculation and secondly the responses of plantlets needs to be predictable and consistent. Commercial inoculants are now readily available in North America and Europe (Mulongoy et al. 1992). Lovato et al. 1992 tested two of these with micropropagated grapevine and pineapple and although there were effects of soil type on the effectiveness of the inocula they concluded that the technical feasibility of a commercial AMF inocula is now proven. The former requirement is now thus at least partly satisfied.

More widespread evaluation of available commercial inocula is now clearly prudent. The most likely outcome will be an appreciation of the need to carefully match inoculum to the micropropagation system, guided by relevant research. With these considerations it is likely that in the future inoculation with AMF will be an integral part of most micropropagation systems. Their application will result in production of plantlets with savings in time, energy and chemical inputs and make micropropagation systems not just more economically competitive but also more sustainable.

\section{References}

Azcon-Aquilar, C., Barcelo, A., Vidal, M.T. \& De La VINA, G. 1992. Further studies on the influence of mycorrhizae on growth and development of micropropagated avocado plants. Agronomie 12: 837-840.

Barea, J. M. \& AzCON-Aguilar, C. 1982. Production of plant growth-regulating substances by the vesiculararbuscular mycorrhizal fungus Glomus mosseae. Applied Environmental Microbiology 43: 810-813.

- AzCon-Aguilar, C. \& Azcon, R. 1993. Mycorrhiza and Crops. In: Tommerup, I.C. (ed.). Advances in Plant Pathology. Mycorrhiza: A Synthesis. Academic Press, New York.

Berta, G., Fusconi, A., Trotta, A. \& Scannerini, S. 1990. Morphogenetic modifications induced by the mycorrhizal fungus Glomus strain $\mathrm{E}_{3}$ in the root system of Allium porrum L. The New Phytologist 114: 207215 .

- Trotta, A., Hooker, J.E., Munro, M., Atkinson, D., Giovanetti, M., Marini., S., Loreti, F., Tisserant, B., Gianinazzi-Pearson, V. \& Gianinazzi, S. 1994. The effects of arbuscular mycorrhizal infection on plant growth, root system morphology and soluble protein content in Prunus cerasifera L. Tree Physiology (in press).

Blal, B., Morel, C., Gianinazzi-Pearson, V., Fardeau, J. C. \& Gianinazzi, S. 1990. Influence of vesiculararbuscular mycorrhizae on phosphate fertiliser efficiency in two tropical acid soils planted with micropropagated oil palm (Elaeis Guineensis Jacq). Biology and Fertility of Soils 9: 43-48.

Bowen, G.D., Bevege, D. \& Mosse, B. 1975. Phosphate physiology of vesicular-arbuscular mycorrhizas. In: Sanders, F.E. et al. (eds.). Endomycorrhizas. Academic Press, London. p. 241-260.
Branzanti, B., Gianinazzi-Pearson, V. \& Gianinazzi, S. 1992. Influence of phosphate fertilization on the growth and nutrient status of micropropagated apple infected with endomycorrhizal fungi during the weaning stage. Agronomie 12: 841-845.

- Gianinazzi-Pearson, V., Gianinazzi, S., Predieri, S. \& BARALDI, R. 1991. Influence of artificial substrata on mycorrhization of micropropagatedfruit trees in a horticultural system. In: Alexander, I.J. et al. (eds.). Mycorrhizas in Ecosystems. CAB International, Oxon, UK. p. 333-339.

Chavez, M.C.G. \& Ferrera-Cerrato, R. 1990. Effect of vesicular-arbuscular mycorrhizae on tissue culture derived plantlets of strawberry. Hort Science 25: 903 905.

Davis, T.D., Haissing, B. E. \& Santchla, N. 1988. Adventitious Root Formation. In: Davis, T.D. et al. (eds.). Advances in Plant Sciences Series. Dioscorides Press, Portland, Oregon. Vol. 2.

De Klerk, G.J. \& Ter Brugge, J. 1992. Factors affecting adventitious root formation in microcuttings of Malus. Agronomie 12: 747-755.

GianinaZZI-PEARSON, V. 1986. Mycorrhizae: a potential for better use of phosphate fertilizer. Fertilizers and Agriculture 92: 1-10.

Gray, L.E. \& Gerdeman, J.W. 1969. Uptake of ${ }^{32} \mathrm{P}$ by vesicular-arbuscular mycorrhizae. Plant and Soil 30: 415-422.

Hooker, J.E., Jaizme-VegA, M. \& Atkinson, D. 1994. Biocontrol of plant pathogens using arbuscular mycorrhizal fungi. In: Impact of Arbuscular Mycorrhizas on Sustainable Agriculture and Natural Ecosystems. Birkhauser, Switzerland.

- Munro, M. \& Atkinson, D. 1992. Vesicular-arbuscu- 
lar mycorrhizal fungi induced alteration in poplar root system morphology. Plant and Soil 145: 207-214.

Lovato, P., Gullemin, J. P. \& Gianinazzi, S. 1992. Application of commercial arbuscular endomycorrhizal fungal inoculants to the establishment of micropropagated grapevine rootstock and pineapple plants. Agronomie 12: 873-880.

Meyer, J. R. \& Lindermann, R. G. 1986. Selective influence of populations of rhizosphere or rhizoplane bacteria and actinomycetes by mycorrhizas formed by Glomus fasciculatum. Soil Biology and Biochemistry 18: 191-196.

Morandi, D., Bailey, J. A. \& Gianinazzi-Pearson, V. 1984. Isoflavonoid accumulation in soybean roots infected with vesicular-arbuscular mycorrhizal fungi. Physiological Plant Pathology 24: 357-364.

Mulongoy, K., Gianinazzi, S., Roger, P. A. \& DommerGUES, Y. 1992. Biofertilisers: agronomic and environmental impacts and economics. In: Da Silva, E. et al. (eds.). Microbial Technology: Economic and Social Aspects. Cambridge University Press, Cambridge. p. 59-69.
O'Riordai N, F. 1992. The European plant tissue culture industry 1990. Agronomie 12: 743-740.

Ravolanirina, F., Gianinazzi, S., Trouvelot, A. \& Carre, M. 1989. Production of endomycorrhizal explants of micropropagated grapevine rootstocks. Agriculture, Ecosystems and Environment 29: 323-327.

Salamanca, C. P., Herrera, M. A. \& Barea, J.-M. 1992. Mycorrhizal inoculation of micropropagated woody legumes used in revegetation programmes for decertified Mediterranean ecosystems. Agronomie 12: 869-872.

Schellenbaum, L., Berta, G., Ravolanirina, F., TisseRant, B., Gianinazzi, S. \& Fitter, A. H. 1991. Influence of endomycorrhizal infection on root morphology in a micropropagated woody plant species (Vitis vinifera L.). Annales of Botany 68: 135-141.

Williams, S.C.K., Vestberg, J., Uosukainen, M., DodD, J.C. \& JEFFRIES, P. 1992. Effects of fertilizers and arbuscular mycorrhizal fungi on the post-vitro growth of micropropagated strawberry. Agronomie 12: 851-857.

Introductory article received June 1994 